\title{
Influence of Glass Powder on Hydration Kinetics of Composite Cementitious Materials
}

\author{
Xiaolin Chang, ${ }^{1}$ Xinping Yang, ${ }^{1}$ Wei Zhou, ${ }^{1}$ Guoshuai Xie, ${ }^{1,2}$ and Shuhua Liu ${ }^{1}$ \\ ${ }^{1}$ State Key Laboratory of Water Resources and Hydropower Engineering Science, Wuhan University, Wuhan 430072, China \\ ${ }^{2}$ Power China Huadong Engineering Corporation, Hangzhou 310014, China \\ Correspondence should be addressed to Shuhua Liu; shliu@whu.edu.cn
}

Received 16 June 2015; Accepted 15 September 2015

Academic Editor: Luigi Nicolais

Copyright (c) 2015 Xiaolin Chang et al. This is an open access article distributed under the Creative Commons Attribution License, which permits unrestricted use, distribution, and reproduction in any medium, provided the original work is properly cited.

\begin{abstract}
The influence of glass powder (GP) on hydration kinetics of composite cementitious materials has been investigated by isothermal calorimetry test and hydration kinetics methods in this paper. The hydration heat emission rate and hydration heat decrease gradually while the induction and acceleration period increase with the increase of GP content. According to Krstulovic-Dabic model, the hydration process of composite cementitious materials containing GP is controlled by a variety of complicated reaction mechanisms, which can be divided into three periods: nucleation and crystal growth (NG), phase boundary reaction (I), and diffusion (D). The NG and I process are shortened after incorporating GP.
\end{abstract}

\section{Introduction}

Nowadays, large amount of industrial and household waste glass has caused some serious environmental pollution and resource waste, which widely attracts the focus of researchers. United Nations statistics show that $7 \%$ of the world's solid waste is waste glass. Chinese annual output is about 1040 million tons, accounting for almost $5 \%$ of total solid waste. But not all waste glass can be recycled to produce new glass because of impurities, high-cost, and various colours $[1,2]$.

Reuse of waste glass in building materials, especially in concrete, is among the most feasible applications for the volume of material involved, the capacity for use of the material in bulk, and the likely ability of construction applications to afford allowances for slight variation in composition or form [3-9]. Many efforts have been made to use waste glass in cement industry as a partial replacement for the coarse or fine aggregates since 1960s [3-6]. In recent years, many works have been conducted for the use of waste glass powder (GP) as a cement replacement. Being amorphous and containing large quantities of silicon and calcium, soda-lime glass, accounting for $80 \%$ of the waste glass, is pozzolanic or even cementitious in theory when it is finely ground enough [7-9]. The main research focus is mainly about the effect of glass powder's fineness on the pozzolanic activity and alkali-silica reaction (ASR). The finer the glass powder, the higher the pozzolanic activity. What is more, when the GP particles are smaller than $300 \mu \mathrm{m}$, it can effectively mitigate the adverse effects caused by ASR and even be used as ASR inhibitor in glass aggregate mortars. Recently, some attempts have been made to use waste glass as raw siliceous materials for the production of Portland cement $[1,9]$. But the effect mechanism of GP on the hydration process of composite cementitious materials is still not clear. Hydration reaction of cement-based materials is divided into three basic processes according to Krstulovic-Dabic model, namely, nucleation and crystal growth (NG), phase boundary reaction (I), and diffusion (D). However, how do the factors which control the reaction rate and mechanism of corresponding stage change after incorporating GP is still unknown. It is indispensable to fully recognize the acting mechanisms of GP in composite cementitious materials and the influencing factors to guarantee its optimum utilization.

The green beer bottle is used to prepare glass powder in this work, because it has been widely used over the world, especially in China. This paper focuses on the influence of GP on hydration kinetics of composite cementitious materials. Hydration heat evolution rate and hydration heat of 
TABLE 1: Chemical compositions of the cementitious materials (mass, \%).

\begin{tabular}{lccccccccccccc}
\hline Compositions & $\mathrm{F}$ & $\mathrm{SiO}_{2}$ & $\mathrm{Al}_{2} \mathrm{O}_{3}$ & $\mathrm{Fe}_{2} \mathrm{O}_{3}$ & $\mathrm{CaO}$ & $\mathrm{MgO}$ & $\mathrm{SO}_{3}$ & $\mathrm{~K}_{2} \mathrm{O}$ & $\mathrm{Na}_{2} \mathrm{O}_{2}$ & $\mathrm{P}_{2} \mathrm{O}_{5}$ & $\mathrm{Cr}_{2} \mathrm{O}_{3}$ \\
\hline OPC & - & 22.71 & 4.57 & 2.85 & 66.10 & 1.90 & 0.37 & 0.68 & 0.15 & - & - \\
$\mathrm{GP}$ & 0.46 & 69.17 & 2.94 & 1.47 & 10.52 & 1.16 & 0.11 & 1.26 & 12.13 & 0.03 & 0.22 \\
\hline
\end{tabular}

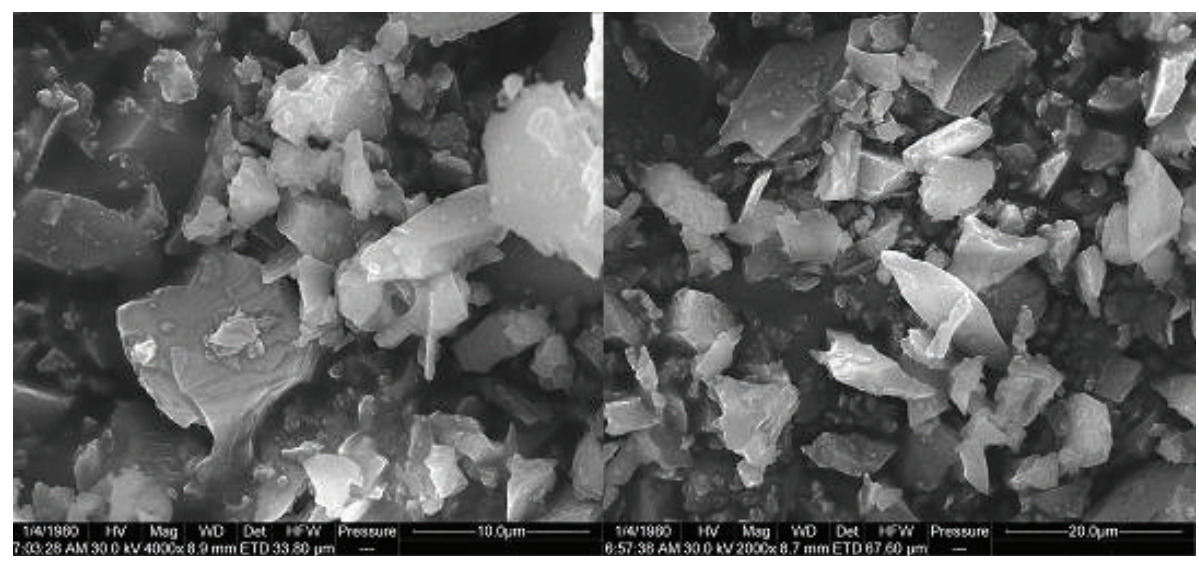

FIgURe 1: Particle morphology of glass powder.

the cement paste containing different GP content are investigated and analysed with the aid of isothermal calorimeter and hydration kinetics methods. This study will contribute to promoting the understanding of hydration mechanism of the composite cementitious materials containing GP.

\section{Experimental}

Ordinary Portland cement P.O 42.5 and GP are used in this test. Among them, GP is made of waste glass bottles, which are crushed and ground for 1 hour in a ball mill. GP particles show irregular singular, blocky, and classic shapes with smooth surface morphology, as shown in Figure 1. And, from Figure 1, expect for some large apparent size, most of GP particle sizes are under $5 \mu \mathrm{m}$. The specific surface area of GP is $515 \mathrm{~m}^{2} / \mathrm{kg}$, which is a little lower than that of cement $\left(385 \mathrm{~m}^{2} / \mathrm{kg}\right)$. The chemical compositions of the raw materials are shown in Table 1 . GP consists of $69.17 \% \mathrm{SiO}_{2}$, $12.13 \% \mathrm{Na}_{2} \mathrm{O}$, and $10.52 \% \mathrm{CaO}$ and is a typical soda-lime glass (approximately $71 \% \mathrm{SiO}_{2}, 13-15 \% \mathrm{Na}_{2} \mathrm{O}$, and $10 \% \mathrm{CaO}$ ).

Mix proportions of paste are shown in Table 2. GP-20 and GP-40 are short for the composite cementitious materials containing $20 \%$ and $40 \%$ GP, respectively. The hydration heat evolution rate and total hydration heat emission of the samples are measured by an isothermal calorimeter (TAM Air) at $25^{\circ} \mathrm{C}$ within 72 hours. The temperature fluctuation is less than $\pm 0.02^{\circ} \mathrm{C}$, and the precision can reach $\pm 20 \mathrm{~m} \mu \mathrm{W}$. The water to binder ratio $(\mathrm{W} / \mathrm{B})$ is 0.4 . The hydration heat evolution rate and total hydration heat of samples can be continuously monitored as a function of time.

\section{Results and Discussions}

3.1. Characteristics of Hydration Heat Evolution. The hydration heat emission rate and the total hydration heat curves
TABLE 2: Mix proportions of samples (mass, \%).

\begin{tabular}{lcc}
\hline Sample & Cement & Glass powder \\
\hline C & 100 & 0 \\
GP-20 & 80 & 20 \\
GP-40 & 60 & 40 \\
\hline
\end{tabular}

of the three samples under the constant temperature of $25^{\circ} \mathrm{C}$ within 72 hours are shown in Figure 2. The end time of induction period and the acceleration period of the three samples are shown in Figure 3. The rate of the second heat emission peak and the total heat emission at different hydration ages determined from heat evolution curves are shown in Table 3.

As shown in Figure 2(a), the hydration processes of the three samples are more or less analogous. During the initial several minutes after mixing the binder with water, an instantaneous exothermic peak occurs sharply, which can be attributed to the rapid dissolving of cement clinker and quick formation of ettringite and syngenite [10-12]. After that, the heat emission rate decreases dramatically accompanied with a slow growth of hydration heat in Figure 2(b), which indicates that the system goes into an induction period. Figure 3 displays that the induction period of sample $\mathrm{C}$ (pure cement) lasts for about 2.57 hours while that of samples GP20 and GP-40 lasts for about 3.38 hours and 3.86 hours, respectively. With the increase of GP content, cement clinker is diluted which brings about the increase of the relative water content and the decrease of the relative $\mathrm{Ca}^{2+}$ concentration in the cementitious system [13-16]. Afterwards, that delays the time when $\mathrm{Ca}^{2+}$ reaches supersaturation, leading to the ending time of the induction period being prolonged.

After the induction period, the acceleration period comes with strong hydration reaction of $\mathrm{C}_{3} \mathrm{~S}$ and fast formation 
TABLE 3: Characteristic values of hydration heat evolution curves of samples at $25^{\circ} \mathrm{C}$.

\begin{tabular}{|c|c|c|c|c|c|}
\hline \multirow{2}{*}{ Sample } & \multirow{2}{*}{$\begin{array}{l}\text { Rate of the second heat } \\
\text { emission peak } q_{\max }(\mathrm{J} / \mathrm{g} \cdot \mathrm{h})\end{array}$} & \multicolumn{4}{|c|}{ Total heat emission $Q(\mathrm{~J} / \mathrm{g})$} \\
\hline & & $12 \mathrm{~h}$ & $48 \mathrm{~h}$ & $60 \mathrm{~h}$ & $72 \mathrm{~h}$ \\
\hline $\mathrm{C}$ & 8.262 & 61.67 & 150.85 & 158.41 & 164.06 \\
\hline GP-20 & 6.973 & 55.18 & 132.61 & 139.49 & 144.71 \\
\hline GP-40 & 5.787 & 54.62 & 103.45 & 108.67 & 117.78 \\
\hline
\end{tabular}

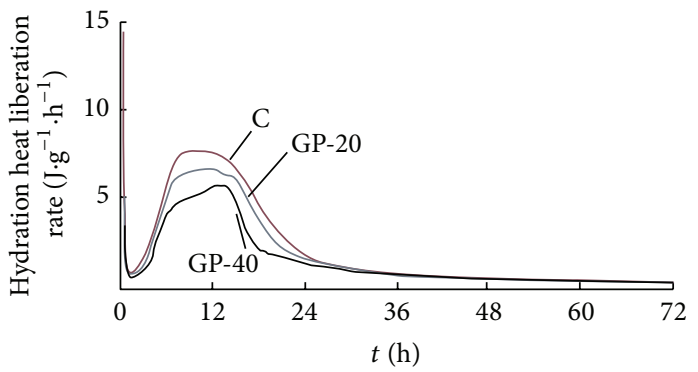

(a)

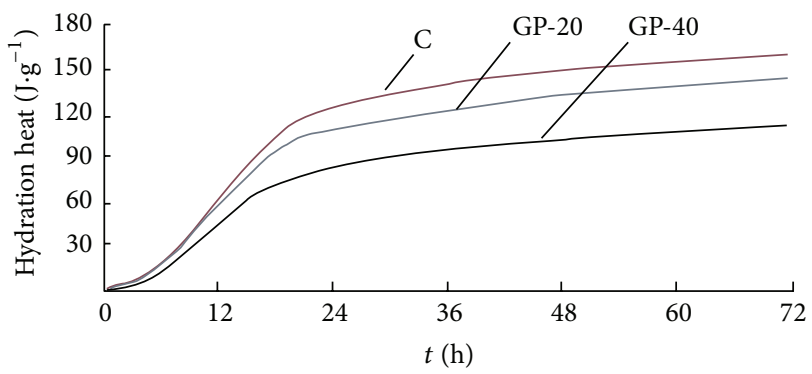

(b)

FIgURE 2: (a) Hydration heat evolution rate and (b) total hydration heat of the cement with and without GP.

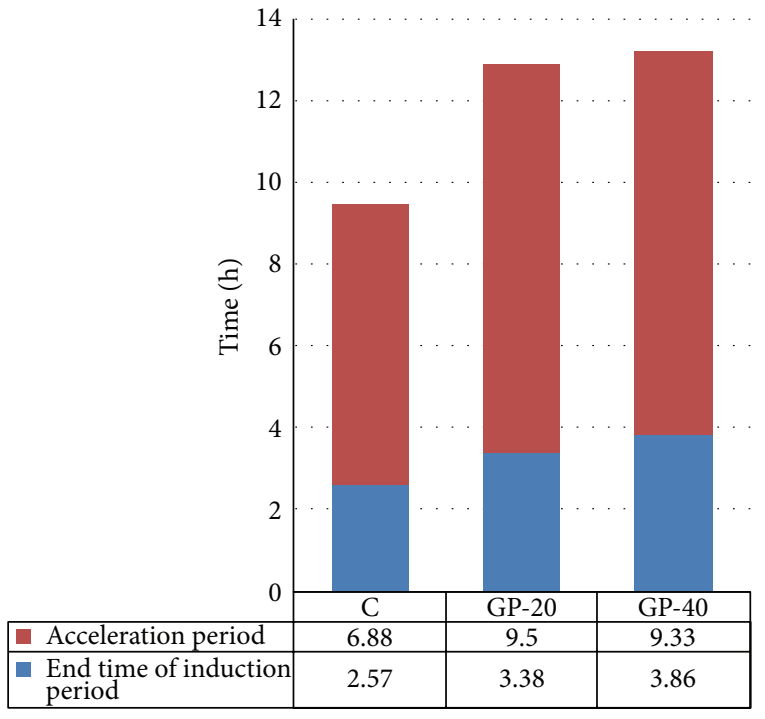

FIGURE 3: The acceleration period and end time of induction period of hydration process.

of C-S-H gel and $\mathrm{Ca}(\mathrm{OH})_{2}$ [17]. As a whole, incorporating $\mathrm{GP}$, to some extent, retards the early hydration process of composite cementitious materials. The higher content of GP, the lower peak value and longer reaching time to the second exothermic peak, as is shown in Figure 2(a) and Table 4 . The maximum value of the second exothermic peak of samples decreases by $15 \%$, from $8.262 \mathrm{~J} / \mathrm{g} \cdot \mathrm{h}$ to $6.973 \mathrm{~J} / \mathrm{g} \cdot \mathrm{h}$, accompanied with its occurring time increasing from 9.45 hours to 12.88 hours after incorporating $20 \%$ GP. When the GP content increases from $20 \%$ to $40 \%$, the time reaching the second exothermic peak is prolonged from 12.88 hours to
TABLE 4: Kinetic factors of hydration process of composite cementitious materials.

\begin{tabular}{lccccccc}
\hline Sample & $N$ & $K_{1}^{\prime}$ & $K_{2}^{\prime}$ & $K_{3}^{\prime}$ & $\alpha_{1}$ & $\alpha_{2}$ & $\alpha_{2}-\alpha_{1}$ \\
\hline C & 1.417 & 0.033 & 0.0115 & 0.0029 & 0.127 & 0.331 & 0.204 \\
GP-20 & 1.256 & 0.035 & 0.0117 & 0.0018 & 0.118 & 0.195 & 0.077 \\
GP-40 & 1.187 & 0.031 & 0.0093 & 0.0011 & 0.105 & 0.178 & 0.073 \\
\hline
\end{tabular}

13.19 hours and the maximum value of the second exothermic peak is decreased by $17 \%$, from $6.973 \mathrm{~J} / \mathrm{g} \cdot \mathrm{h}$ to $5.787 \mathrm{~J} / \mathrm{g} \cdot \mathrm{h}$. The low hydration activity of GP may be the main affecting factor.

Figure 2(b) shows the total hydration heat of samples, which decreases disproportionally with the increase of GP content. It can be seen from Table 4 that the 12 hours' heat emission decreases by $10.52 \%$ from $61.67 \mathrm{~J} / \mathrm{g}$ to $55.18 \mathrm{~J} / \mathrm{g}$ after incorporating $20 \% \mathrm{GP}$ and decreases by $1.01 \%$ from $55.18 \mathrm{~J} / \mathrm{g}$ to $54.62 \mathrm{~J} / \mathrm{g}$ when the GP content increases from $20 \%$ to $40 \%$. The 72 hours' heat emission decreases by $11.79 \%$ from $164.06 \mathrm{~J} / \mathrm{g}$ (sample C) to $144.71 \mathrm{~J} / \mathrm{g}$ (sample GP-20) and by $26.12 \%$ from $144.71 \mathrm{~J} / \mathrm{g}$ (sample GP-20) to $117.78 \mathrm{~J} / \mathrm{g}$ (sample GP-40).

When all the experiment results are normalized to the amount of cement present, both hydration heat and hydration heat emission rate increase with the increase of GP content, which indicates that GP contributes to promoting the hydration of cement. On one hand, the replacement of cement by GP increases the effective water to cement ratio, and there is more space for the hydration products of cement. On the other hand, GP with enough fineness can also act as nucleation site for the cement hydration products to deposit and grow up during the process of nucleation and crystal growth [18-21]. 


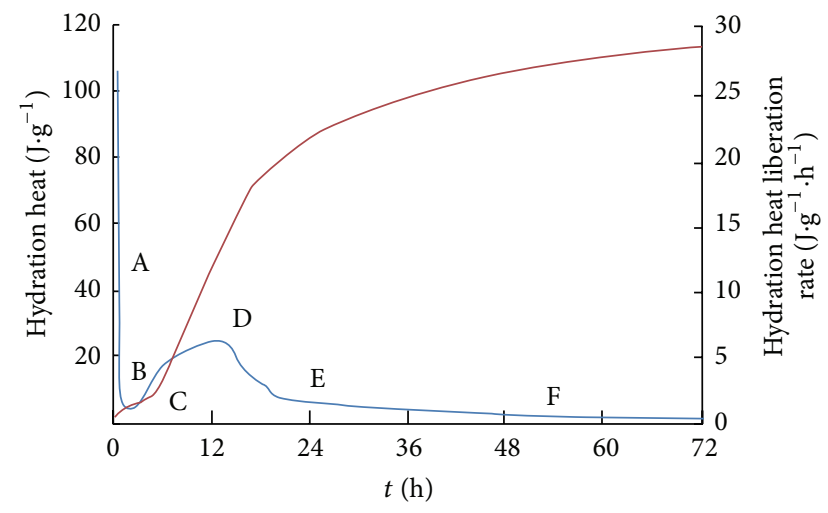

Figure 4: Hydration heat and hydration heat emission rate curves of GP-40.

\subsection{Hydration Process Simulation}

3.2.1. Exothermic Process Division. Take the sample containing 40\% GP (GP-40), for example, as shown in Figure 4. The hydration progress of composite cementitious materials can be generally divided into five processes [22-25]: 0-A-B, BC, C-D, D-E, and E-F. In which, 0-A-B is the acute instant reaction period which is considered as chemical reaction only and not being taken into consideration in the kinetics model. And $\mathrm{B}-\mathrm{C}$ is the induction period during which the hydration rate is nearly back to zero. After that, at the end of C-D acceleration period, the secondary exothermic peak occurs. Deceleration phase D-E and recession period E-F come after the acceleration period, during which the hydration reaction decreases rapidly and then trends to be stationary.

During the first process of hydration, the reaction is so transient with little hydration heat. Meanwhile, due to the low hydration rate during the induction period, the continuous heat quality of induction period can also be ignored. In current research, the hydration process is mainly from the end of induction period to the deceleration phase and recession period.

3.2.2. Hydration Kinetics Model. As a branch of physical chemistry, chemical kinetics focuses on the study of chemical reaction rate and mechanism. Its research object is the nonequilibrium dynamic system changing with time. So the time is an extremely important parameter. Phenomenological dynamics method and molecular reaction dynamics method are the two main research methods $[15,16]$. For heterogeneous reaction system, dynamic formula at a constant temperature can be expressed as follows:

$$
\frac{d \alpha}{d t}=A e^{-E / R T} f(\alpha),
$$

where $\alpha$ is reaction degree of reactants, $R$ is Avogadro constant, $A$ is preexponential factor, $E$ is apparent activation energy, $T$ is the thermodynamic temperature, $t$ is time, and $f(\alpha)$ is function of conversion degree.

According to Krstulovic-Dabic model $[14,16]$, hydration reaction of cement-based materials can be divided into three processes, namely, nucleation and crystal growth (NG), phase boundary reaction (I), and diffusion (D). These three control processes may occur simultaneously or in pairs, or even alone, but the hydration rate of the overall development process depends on the one which reacts slowest; that is, the control process of the slowest reaction controls the reaction rate and mechanism of corresponding stage [1417]. Formula (2)-(4) would be the reflection of the three hydration processes which are controlled by NG, I, and D, respectively:

$$
\begin{aligned}
& \frac{d \alpha}{d t}=F_{1}(\alpha)=K_{1} n(1-\alpha)[-\ln (1-\alpha)]^{n-1 / n} \\
& \frac{d \alpha}{d t}=F_{2}(\alpha)=3 K_{2} R^{-1}(1-\alpha)^{2 / 3} \\
& \frac{d \alpha}{d t}=F_{3}(\alpha)=\frac{3}{2} \frac{\left[K_{3} R^{-2}(1-\alpha)^{2 / 3}\right]}{\left[1-(1-\alpha)^{1 / 3}\right]}
\end{aligned}
$$

where $K_{1}, K_{2}$, and $K_{3}$ are reaction rate constant and $n$ is reaction order.

As $R$ is a constant, to make simplification, $K_{1}=K_{1}^{\prime}$, $K_{2} R^{-1}=K_{2}^{\prime}$, and $K_{3} R^{-2}=K_{3}^{\prime}$.

Reaction degree of reactants and maximum hydration heat $Q_{\max }$ can be expressed $[11,14]$ and calculated from the following formula:

$$
\begin{aligned}
\alpha & =\frac{Q}{Q_{\max }}, \\
\frac{d \alpha}{d t} & =\frac{d Q}{d t} \cdot \frac{1}{Q_{\max }}, \\
\frac{1}{Q} & =\frac{1}{Q_{\max }}+\frac{t_{50}}{Q_{\max }\left(t-t_{0}\right)},
\end{aligned}
$$

where $Q$ is accumulated hydration heat at the time of $t, Q_{\max }$ is maximum hydration heat, $t_{0}$ is the end time of induction period, and $t_{50}$ is the time when the hydration heat value is half of $Q_{\max }$.

This model is a considerable hydration dynamic model which made researchers find it easy to understand the controlling factors at each stage for composite cementitious materials. At the same time, there are also some limits to this model. Take the boundaries between the three processes as an example; it is still difficult to be divided accurately and the correlation between the experimental data and models at the boundaries is also poor. Despite this, attempts have been made to use Krstulovic-Dabic model to simulate the hydration process of composite cementitious materials containing GP in this paper.

3.2.3. Hydration Process Simulation of Composite Cementitious Materials with and without GP. $Q_{\max }$ can be deduced and calculated according to Knudsen extrapolation equation [14], formula (7), as is shown in Figure 5. Kinetics parameters $K_{1}^{\prime}$ and $n$ under NG process would be deduced and calculated by formula (2) when transforming to linear regression of $\ln [-\ln (1-\alpha)]=n \ln K_{1}^{\prime}+n \ln \left(t-t_{0}\right)$, as is shown in Figure 6. 


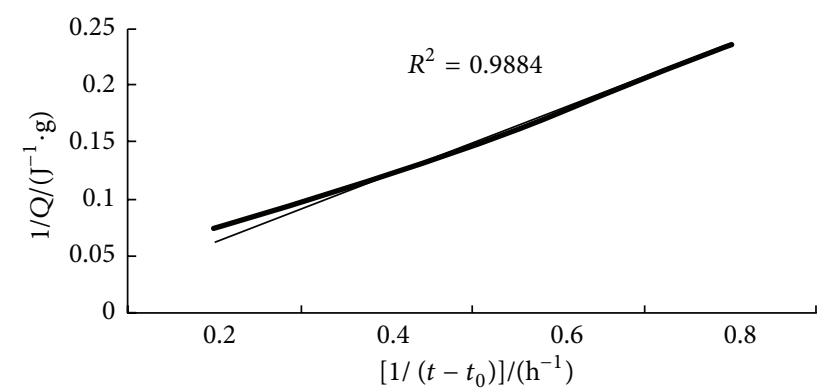

FIGURE 5: Determination of maximum hydration emission heat $Q_{\max }$ from linear regression.

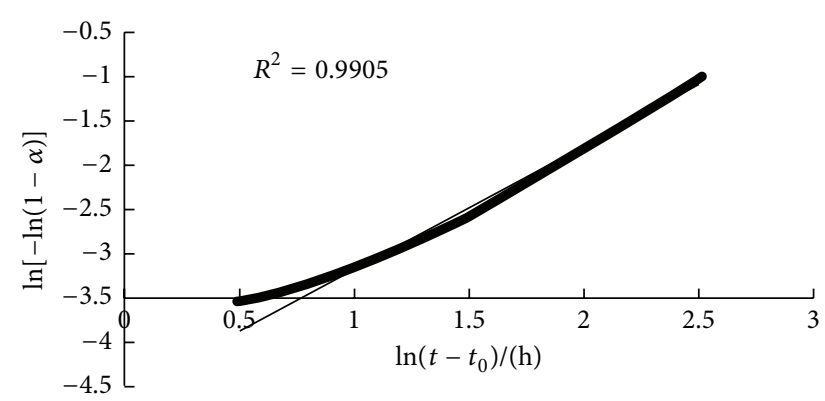

FIGURE 6: Determination of kinetic factors ( $n$ and $K_{1}^{\prime}$ ) of nucleation and crystal growth (NG) process from linear regression.

$K_{2}^{\prime}$ under process I and $K_{3}^{\prime}$ under process $\mathrm{D}$ would be deduced and calculated using the same method. All the parameters of the three samples are shown in Table 4. Theoretical and practical hydration curves of the three samples are shown in Figures 7-9.

As shown in Figures 7-9, theoretical curves $F_{1}(\alpha), F_{2}(\alpha)$, and $F_{3}(\alpha)$ simulated by Krstulovic-Dabic model are compared with practical $d \alpha / d t$ curve deduced from experimental data. The intersection point $\alpha_{1}$ is the turning points from nucleation and crystal growth (NG) process to phase boundary reaction (I) process and $\alpha_{2}$ is the turning points from phase boundary reaction (I) to diffusion (D) process. Different hydration mechanisms are revealed in different period. Hydration mechanisms of samples can be inferred and determined by comparing $\alpha_{1}$ and $\alpha_{2}$.

Figure 7 shows the simulated and practical hydration exothermic rate curves of cement sample. There is one part of curves for $F_{1}(\alpha), F_{2}(\alpha)$, and $F_{3}(\alpha)$, matching with experimental hydration curve $d \alpha / d t$, respectively. The hydration degree of the time point corresponding to the end of induction period for cement sample is 0.04 . During 0.04 and $\alpha_{1}$, curve of $F_{1}(\alpha)$ is identical with the practical $d \alpha / d t$. Theoretical curve of $F_{2}(\alpha)$ is consistent with $d \alpha / d t$ between $\alpha_{1}$ and $\alpha_{2}$. $F_{3}(\alpha)$ is consistent with curve $d \alpha / d t$ between $\alpha_{2}$ and 1 . Results validate that cement hydration has a complicated process with multiple reaction mechanisms. The controlling factor is different during different hydration process.

During the early hydration period, reactants, especially for water, are rich while the hydration products are poor,

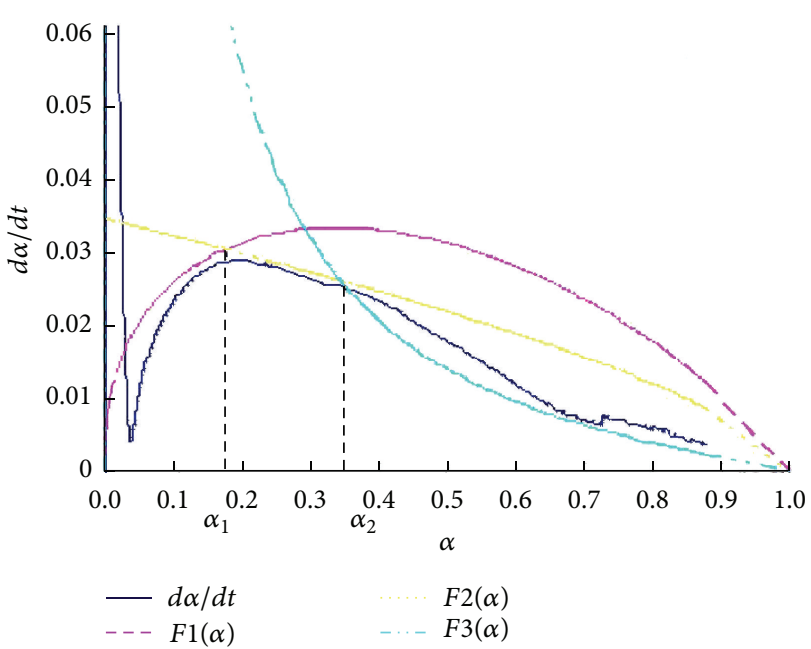

Figure 7: Hydration rate curves of sample C.

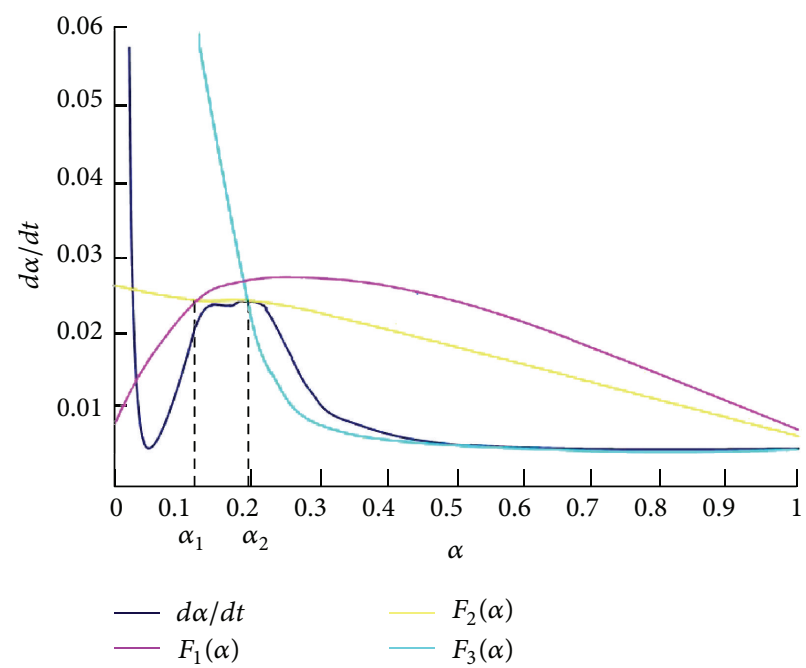

Figure 8: Hydration rate curves of sample GP-20.

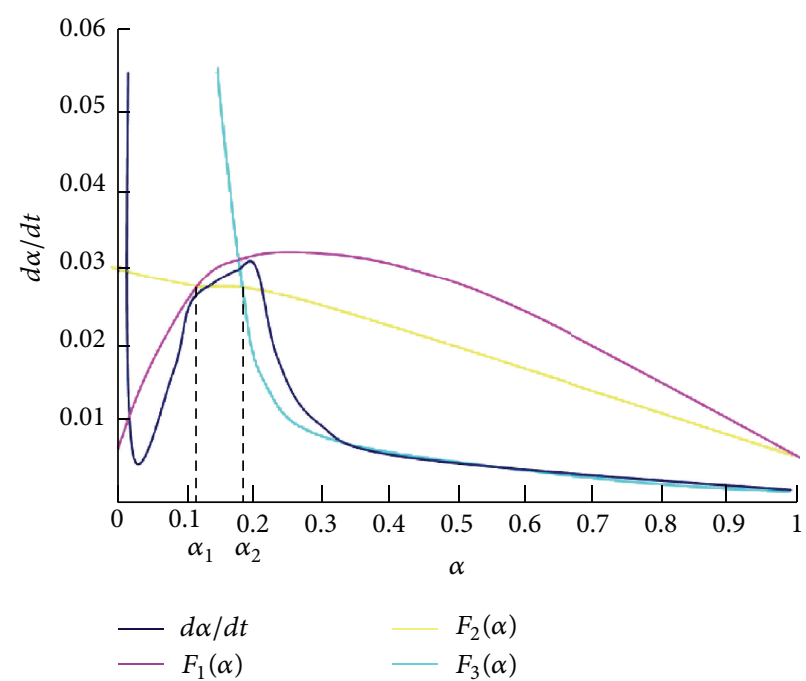

FIGURE 9: Hydration rate curves of sample GP-40. 
so that hydration in early stage is mainly controlled by the crystallization nucleation and crystal growth, during which chemical reaction of hydration is strong [11]. With the development of hydration, the hydration products become more and more accompanied with large amount of water consumed, which causes the ion migration to be relatively difficult [11]. Therefore, the hydration mechanism changes to phase boundary reaction or diffusion, during which physical diffusion is strong and hydration is relatively slow with a stable development.

Figures 8 and 9 display the simulated and practical hydration exothermic rate curves of GP-20 and GP-40. In comparison with pure cement, the fitting results of samples containing GP have a slight deviation but they still show high goodness of fit with the practical hydration heat evolution rate curve. So the Krstulovic-Dabic model can also be used to simulate the hydration of composite cementitious materials containing GP, which is also capable of revealing the development trends and controlling factors of hydration process to some degree.

Similar to pure cement, the hydration process of composite cementitious materials that mixed $20 \%$ and $40 \%$ GP is also controlled by a variety of complex reaction mechanisms belonging to the process of NG-I-D. But it is noted that both of the hydration durations for NG process and I process are shorter than those of pure cement. The value of $\alpha_{1}$ decreases from 0.127 to 0.118 while value of $\left(\alpha_{2}-\alpha_{1}\right)$ is decreasing from 0.204 to 0.077 after incorporating $20 \%$ GP. When the GP content increases from $20 \%$ to $40 \%$, the value of $\alpha_{1}$ continues to decrease from 0.118 to 0.105 along with value of $\left(\alpha_{2}-\alpha_{1}\right)$ decreasing from 0.077 to 0.073 . This may be associated with the fineness and the low water absorption of GP. Replacement of cement by GP increases the effective water to cement ratio and provides more space for the hydration products of cement in the early hydration process. Meanwhile, GP with enough fineness can also act as nucleation site for the cement hydration products to deposit and grow up during the process of nucleation and crystal growth $[6,26,27]$. Both of those may contribute to strengthening the controlling effects of NG and I by promoting the hydration of cement, leading to a sharper exothermic rate peak and shorter hydration duration.

\section{Conclusions}

(1) The hydration heat emission rate and hydration heat decrease gradually while the induction and acceleration period increase with the increase of GP content.

(2) Similar to cement, the Krstulovic-Dabic model can also be used to simulate the hydration process of composite cementitious materials containing GP. The hydration process of composite cementitious materials containing GP is controlled by a variety of complicated reaction mechanisms, which can be divided into three periods: nucleation and crystal growth (NG), phase boundary reaction (I), and diffusion (D).

(3) The NG and I process of the composite cementitious materials are shortened after incorporating GP.

\section{Conflict of Interests}

The authors declare that there is no conflict of interests regarding the publication of this paper.

\section{Acknowledgments}

This project is funded by the National Natural Science Foundation of China (51208391) and National Basic Research Program of China (973 Program, 2013CB035901).

\section{References}

[1] C. J. Shi and K. R. Zheng, "A review on the use of waste glasses in the production of cement and concrete," Resources, Conservation and Recycling, vol. 52, no. 2, pp. 234-247, 2007.

[2] J. H. Song, "Waste glass treatment and resource-like utilization," Heilongjiang Environmental Journal, vol. 34, no. 4, pp. 68-70, 2010.

[3] C. D. Johnston, "Waste glass as coarse aggregate for concrete," Journal of Testing and Evaluation, vol. 2, no. 5, pp. 344-350, 1974.

[4] A. Karamberi and A. Moutsatsou, "Participation of coloured glass cullet in cementitious materials," Cement and Concrete Composites, vol. 27, no. 2, pp. 319-327, 2005.

[5] I. B. Topçu and M. Canbaz, "Properties of concrete containing waste glass," Cement and Concrete Research, vol. 34, no. 2, pp. 267-274, 2004

[6] M. J. Terro, "Properties of concrete made with recycled crushed glass at elevated temperatures," Building and Environment, vol. 41, no. 5, pp. 633-639, 2006.

[7] S. H. Liu, G. S. Xie, and M. J. Rao, "Effect of waste glass powder on properties and microstructure of ultrahigh performance cement based materials," Material Research Innovations, vol. 17, supplement 1, pp. 210-214, 2013.

[8] S. H. Liu, G. S. Xie, and S. Wang, "Effect of curing temperature on hydration properties of waste glass powder in cement-based materials," Journal of Thermal Analysis and Calorimetry, vol. 119, no. 1, pp. 47-55, 2015.

[9] C. Shi, Y. Z. Wu, C. Riefler, and H. Wang, "Characteristics and pozzolanic reactivity of glass powders," Cement and Concrete Research, vol. 35, no. 5, pp. 987-993, 2005.

[10] J. W. Bullard, H. M. Jennings, R. A. Livingston et al., "Mechanisms of cement hydration," Cement and Concrete Research, vol. 41, no. 12, pp. 1208-1223, 2011.

[11] S. H. Liu, L. Wang, Y. X. Gao, B. Yu, and W. Tang, "Influence of fineness on hydration kinetics of supersulfated cement," Thermochimica Acta, vol. 605, no. 1, pp. 37-42, 2015.

[12] B. Lothenbach, K. Scrivener, and R. D. Hooton, "Supplementary cementitious materials," Cement and Concrete Research, vol. 41, no. 12, pp. 1244-1256, 2011.

[13] X.-Y. Wang, H.-S. Lee, K.-B. Park, J.-J. Kim, and J. S. Golden, "A multi-phase kinetic model to simulate hydration of slagcement blends," Cement and Concrete Composites, vol. 32, no. 6, pp. 468-477, 2010.

[14] P. Y. Yan and F. Zheng, "Kinetics model for the hydration mechanism of cementitious materials," Kuei Suan Jen Hsueh Pao/ Journal of the Chinese Ceramic Society, vol. 34, no. 5, pp. 555$559,2006$.

[15] A. Fernandez-Jimenez, F. Puertas, and A. Arteaga, "Determination of kinetic equations of alkaline activation of blast furnace 
slag by means of calorimetric data," Journal of Thermal Analysis and Calorimetry, vol. 52, no. 3, pp. 945-955, 1998.

[16] R. Krstulović and P. Dabić, "A conceptual model of the cement hydration process," Cement and Concrete Research, vol. 30, no. 5, pp. 693-698, 2000.

[17] F. Lin and C. Meyer, "Hydration kinetics modeling of Portland cement considering the effects of curing temperature and applied pressure," Cement and Concrete Research, vol. 39, no. 4, pp. 255-265, 2009.

[18] T. D. Dyer and R. K. Dhir, "Chemical reactions of glass cullet used as cement component," Journal of Materials in Civil Engineering, vol. 13, no. 6, pp. 414-417, 2001.

[19] J. A. Jain and N. Neithalath, "Chloride transport in fly ash and glass powder modified concretes-influence of test methods on microstructure," Cement and Concrete Composites, vol. 32, no. 2, pp. 148-156, 2010.

[20] B. R. Patagundi and R. T. Jadhav, "Effect of freezing and thawing on the properties of SFRC containing waste glass powder as pozzolana," International Archive of Applied Sciences and Technology, vol. 3, no. 1, pp. 33-39, 2012.

[21] B. R. Patagundi and K. B. Prakash, "Effect of temperature on the properties of concrete containing glass powder as pozzolana," International Archive of Applied Sciences and Technology, vol. 1, no. 8, pp. 1-4, 2012.

[22] N. Schwarz and N. Neithalath, "Influence of a fine glass powder on cement hydration: comparison to fly ash and modeling the degree of hydration," Cement and Concrete Research, vol. 38, no. 4, pp. 429-436, 2008.

[23] N. Schwarz, H. Cam, and N. Neithalath, "Influence of a fine glass powder on the durability characteristics of concrete and its comparison to fly ash," Cement and Concrete Composites, vol. 30, no. 6, pp. 486-496, 2008.

[24] S. de Castro and J. de Brito, "Evaluation of the durability of concrete made with crushed glass aggregates," Journal of Cleaner Production, vol. 41, no. 1, pp. 7-14, 2013.

[25] J. M. Khatib, E. M. Negim, H. S. Sohl, and N. Chileshe, "Glass powder utilization in concrete production," European Journal of Applied Sciences, vol. 4, no. 3, pp. 98-100, 2012.

[26] C. J. Shi, Y. Z. Wu, C. Riefler, and H. Wang, "Characteristics and pozzolanic reactivity of glass powders," Cement and Concrete Research, vol. 35, no. 5, pp. 987-993, 2005.

[27] R. Idir, M. Cyr, and A. Tagnit-Hamou, "Use of fine glass as ASR inhibitor in glass aggregate mortars," Construction and Building Materials, vol. 24, no. 7, pp. 1309-1312, 2010. 

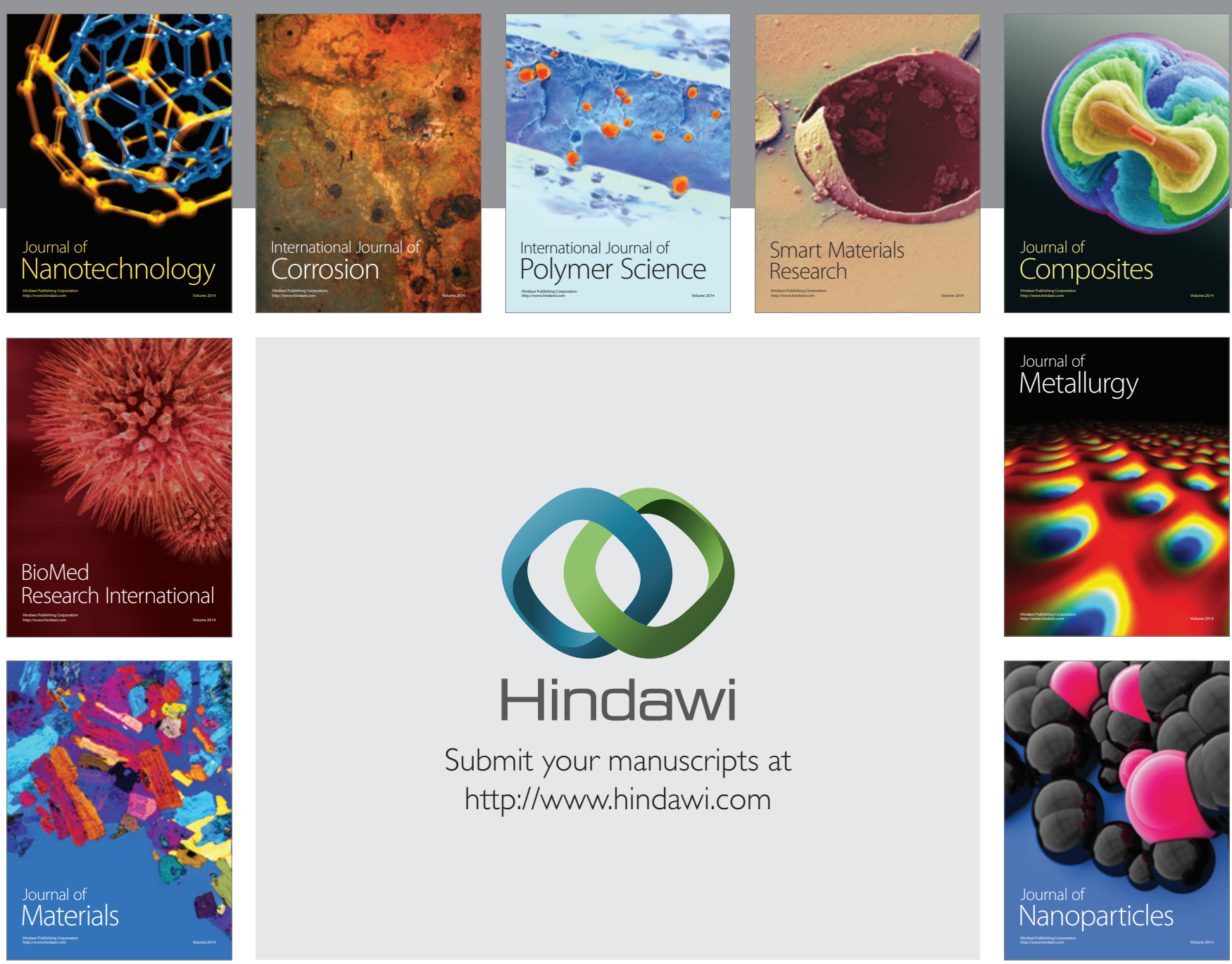

Submit your manuscripts at http://www.hindawi.com
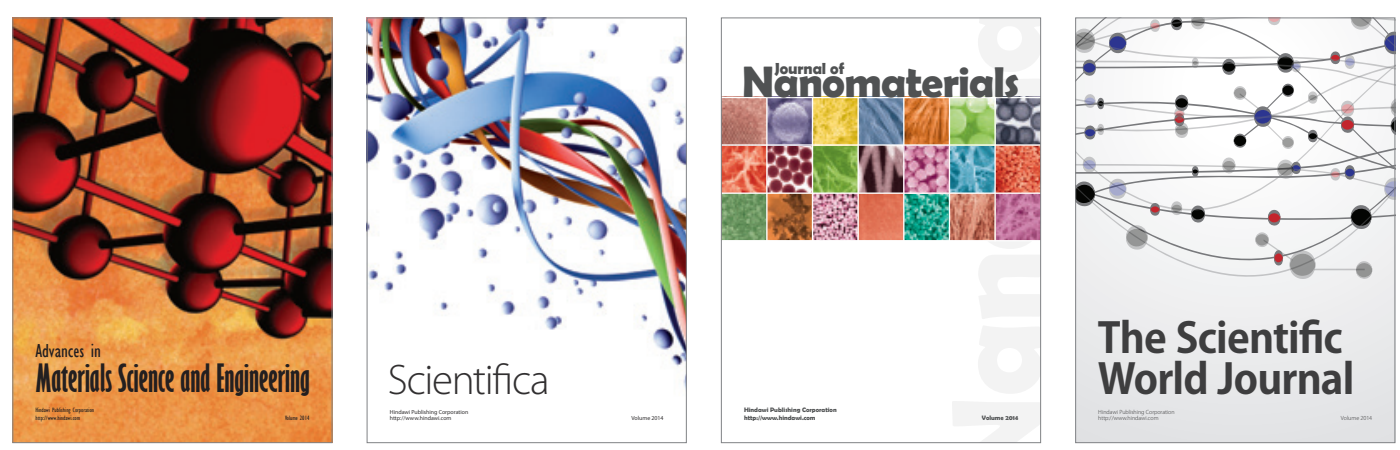

\section{The Scientific World Journal}
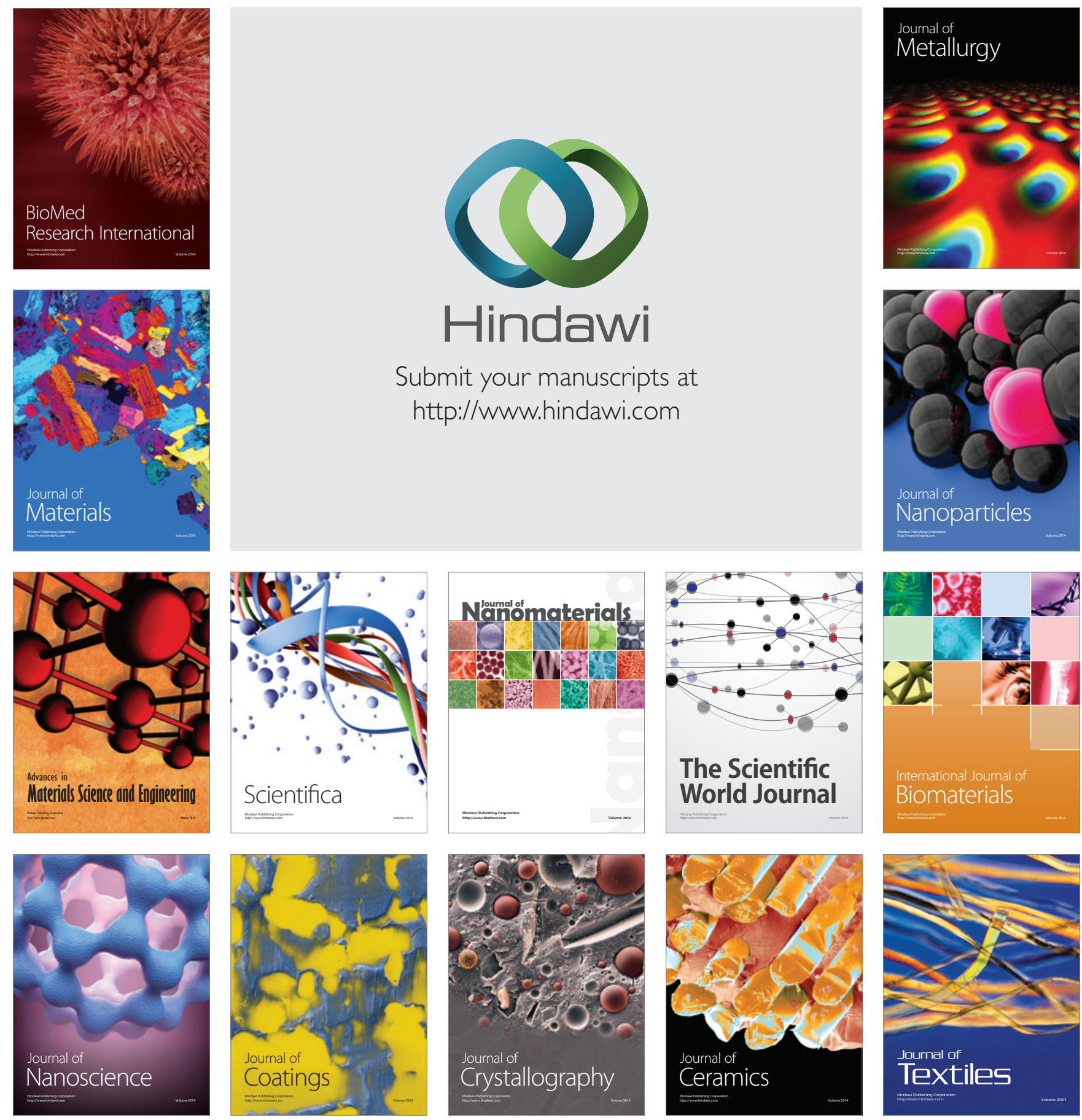